\title{
Prestige Bias: An Obstacle to a Just Academic Philosophy
}

\author{
HELEN DE CRUZ \\ Oxford Brookes University
}

\begin{abstract}
This paper examines the role of prestige bias in shaping academic philosophy, with a focus on its demographics. I argue that prestige bias exacerbates the structural underrepresentation of minorities in philosophy. It works as a filter against (among others) philosophers of color, women philosophers, and philosophers of low socioeconomic status. As a consequence of prestige bias our judgments of philosophical quality become distorted. I outline ways in which prestige bias in philosophy can be mitigated.
\end{abstract}

\section{Introduction}

In spite of a growing realization that academic philosophy has consistently exhibited a lack of diversity, the profession remains largely white, middle-class, male, and Anglophone. Attempts to diversify philosophy, for instance, by introducing more minority authors in syllabi, have met with mixed success. Thompson, Adleberg, Sims, and Nahmias (2016) found that including more women in introductory syllabi did not, on its own, entice more women to major in philosophy. Philosophy students already come to university with preconceived notions about what sort of person a philosopher is: University of Sydney female undergraduates, for example, were both less interested in philosophy and less selfconfident about their philosophical skills compared to their male peers (Baron, Dougherty, \& Miller 2015).

Several psychological factors might contribute to this lack of diversity, including implicit bias and stereotype threat (see Brownstein \& Saul 2016 for a review). One underexplored factor is prestige bias, which is widespread in academia. In this paper "prestige bias" denotes a preference, all other things being equal, for job candidates who have their $\mathrm{PhD}$ degree from prestigious

Contact: Helen de Cruz <hde-cruz@brookes.ac.uk> 
institutions. It also denotes a preference for papers in journals that are seen as prestigious.

The aim of this paper is to investigate how prestige bias contributes to and exacerbates the structural underrepresentation of minorities ${ }^{1}$ in philosophy, and how it amplifies inequalities in access to social and economic resources. Philosophers affected by prestige bias include, but are not limited to, women, African American, Hispanic, and other philosophers of color and people of low socioeconomic status, especially first-generation college graduates. ${ }^{2}$

Section 2 will examine how prestige bias is at present unchallenged compared to other forms of bias in philosophy. Section 3 looks at the forms prestige bias takes in academia, and in philosophy specifically. In Section 4 I consider a common defense of relying on prestige: it may be a useful heuristic of quality. However, as I will argue in Section 5, using prestige as a proxy for quality effectively screens out philosophers from underrepresented groups. Because of these patterns of exclusion, it is unlikely that prestige would be a reliable measure of quality. In Section 6, I outline concrete ways in which we can mitigate prestige bias.

\section{Prestige Bias: An Unchallenged Phenomenon in Philosophy}

Philosophers are increasing their efforts to counter sexism, racism, homophobia, and other forms of bias that marginalize and exclude members of the profession. For example, the Gendered Conference Campaign ${ }^{3}$ was launched by bloggers at Feminist Philosophers to highlight male-only conferences in philosophy. The anonymous blog What is it Like to be a Woman in Philosophy ${ }^{4}$ provides testimonies of women in philosophy, including many accounts of gender and sexual harassment. The Job Candidate Mentoring Program for Women in Philosophy 5 pairs up female mentors and mentees as a way to mitigate the advantage in informal mentoring that many male academic job seekers have. The Cocoon Job-

1. By minorities, I mean people who are underrepresented in philosophy, especially in comparison to their prevalence in the general population. For example, women comprise $50.8 \%$ of the US population, but only between 21 and $26 \%$ of US philosophy faculty members are women (Schwitzgebel \& Jennings 2017). To give another example, Latinx/Hispanics make up $17.6 \%$ of the US population, but only $7.8 \%$ of APA members in 2016 self-identified as such: http://c.ymcdn.com/ sites/www.apaonline.org/resource/resmgr/data_on_profession/Member_Demo_Chart_FY2016_ rev.pdf

2. I will assume that diversity in philosophy is a good thing, but I will not argue for this claim.

3. https://feministphilosophers.wordpress.com/gendered-conference-campaign/

4. https://beingawomaninphilosophy.wordpress.com/

5. https://jobmentoringforwomen.wordpress.com/ 
Market Mentoring Project ${ }^{6}$ helps mentees with other special job market challenges, such as first-generation college graduates and ethnic minorities. Dialogues on Disability ${ }^{7}$ presents a series of interviews that recount the lived experience of disabled philosophers, and draws attention to the systematic underrepresentation and exclusion of disabled philosophers in professional philosophy. The Directory of Philosophers from Underrepresented Groups in Philosophy (UP Directory $)^{8}$ provides a database of philosophers who self-identity with a number of demographics (including Black, with a disability, woman, other gender, and Lesbian, Gay, Bisexual, Transgender or Queer). The purpose of this website, according to its organizers, is "to provide an easy-to-use resource for anyone who wants to learn more about the work of philosophers who belong to underrepresented groups within the discipline." There are committees of the American Philosophical Association (APA) for women, Asian, African-American, Hispanic, LGBTQ, and indigenous philosophers. This selection of efforts within the profession is not meant to be exhaustive but to highlight the fact that some philosophers care about inclusiveness in the discipline.

In all these efforts to increase the discipline's diversity, prestige bias is rarely discussed or directly challenged. This is perhaps due to the large attention implicit bias has received, or active resistance against people who call out bias (see Kidd 2017 for an overview). Some authors, such as Bruya (2015), have offered methodological criticisms of rankings of philosophical programs, in particular of the Philosophical Gourmet Report (PGR), but do not dispute the idea of ranking per se. Their focus is on how the rankings could be improved, but they do not seem to think there is anything intrinsically wrong with a ranking system. However, as I will argue in the next sections, rankings reflect a bias for prestige, and prestige bias can exacerbate inequalities in philosophy.

\section{Prestige Bias Is Pervasive}

Academics in the US tend to be politically left-leaning: the majority are in favor of lessening economic and social inequalities (Gross \& Simmons 2014). However, this concern for equality of opportunity does not translate itself in faculty hiring decisions. Social inequality in academia is glaring. A main criterion for hiring appears to be the prestige of the department where candidates complete their

6. https://sites.google.com/site/cocoonmentoringproject/

7. See, e.g., this interview, with Brian Montgomery. http://philosophycommons.typepad. com/disability_and_disadvanta/2017/10/dialogues-on-disability-shelley-tremain-interviews-bri an-montgomery.html. See also https://www.academia.edu/5812065/Introducing_Feminist_Philosophy_of_Disability.

8. http://www.theupdirectory.com 
doctorate. (There are other ways in which prestige bias manifests itself, such as a bias in favor of prestigious journals or for what are perceived as "core topics", which I will briefly discuss in Section 5.2.) In particular, there is a structural lack of upward social mobility in hiring practices: someone from a prestigious school may end up in a lower-ranked institution, but the reverse is unusual. In philosophy, as in other disciplines, comparably few high-prestige schools generate a disproportionate number of tenure-track hires. This advantage of prestigious institutions also appears in graduate school admissions, citations, and research assessments. The data I will present in this section are correlational and do not, by themselves, establish that prestige is driving the hiring decisions. It might be that a common factor (e.g., candidate quality) underlies the pattern. In Section 4 I will present evidence to suggest that prestige-independent of other measures - is driving hiring decisions.

A systematic review of placement data of 19,000 academics in three disciplines, computer science, business, and history (Clauset, Arbesman, \& Larremore 2015) shows that candidates graduating from prestigious schools have a substantial advantage on the job market: only $25 \%$ of doctoral schools produced $71-86 \%$ of all tenure-track faculty in these fields. Upward social mobility was especially rare: only $9-14 \%$ of faculty found jobs in institutions that were more prestigious than the one that awarded their doctorate. Herlihy-Mera (2015) observes similar hiring patterns in English departments in the US from 1955 to 2012. High-ranking universities supplied lower-ranking ones with plenty of candidates, but they did not reciprocally hire from these schools: $72 \%$ of all hires came from top-10 departments, but only $1 \%$ of hires in top-10 departments are $\mathrm{PhD}$ holders from lower-ranked schools. Moreover, the top-1o departments mostly hire candidates from similarly prestigious universities. Overall, $50 \%$ of appointments in this field came from just $3 \%$ of institutions.

Do we observe similar dynamics in philosophy? I examined hiring data from the past 5 years (2012-2017), obtained by Carolyn Dicey Jennings and colleagues through their Academic Placement Data and Analysis project ${ }^{9}$ to find out whether prestige of the department that awarded the PhD influences hiring. I use the PGR as a measure of prestige. In the PGR, a select number of judges (mostly from elite institutions in the US and the UK) rank philosophy departments with graduate programs in the English-speaking world "on the basis of the quality of faculty." 10 Note that by its focus on Anglophone departments, the PGR does not include institutions in many parts of the world, including continental Europe, Latin America, Asia, and Africa. In this way, it may further exacerbate discrimination against non-native speakers of English, for instance caused by implicit

9. http://placementdata.com/about/

10. The 2015-2016 PGR was found and retrieved from this address: http://www.philosophi calgourmet.com/reportdesc.asp. The 2017-2018 version can be found here: http://34.239.13.205/ 
and explicit biases against people who speak with a foreign accent (see Ayala 2015 for discussion). Also, with the exception of the National University of Singapore, African and Asian universities in English-speaking countries are not featured in the PGR, even though a number of them offer PhDs in Philosophy with English as the language of instruction, which further strengthens biases against people of color in philosophy.

The PGR provides a good indicator of the relative prestige of philosophy faculties. Its top-ranked schools mostly correspond to departments that also do well in other rankings (e.g., Oxford, Princeton, Yale, and Harvard); however, there are a few schools, such as Rutgers and Michigan, which rank highly in the PGR but not globally. ${ }^{11}$ To investigate placements in philosophy, Jennings et al. requested placement data from department chairs and placement officers. ${ }^{12}$ Their dataset contains a diverse set of unranked and ranked doctoral programs. Examples of unranked participating schools include Baylor University, the University of Reading, Boston University, Duquesne University, Emory University, and Fordham University. Examples of ranked participating schools include the University of Oxford, the Graduate Center of the City University of New York, Princeton University, the University of Toronto, and New York University. If philosophy is like other disciplines, we should observe the following patterns. First, one would expect that the top-ranked departments supply a very large number of tenure-track hires. Second, graduates from the most prestigious departments would be hired at all levels, whereas graduates from unranked schools tend to cluster at unranked or lowly ranked institutions. I focused on tenure-track hires and permanent lectureships (the equivalent junior faculty position in the United Kingdom, Australia, and New Zealand) in the dataset. As I wanted to examine the effects of doctoral prestige, I only looked at doctoral departments in countries that are listed in the PGR (the US, UK, Canada, New Zealand, and Australia). The resulting dataset of hires from 2012 to $2017^{13}$ (2012-2017) contains 1260 tenure-track and permanent lecturer hires, 1254 of which have information on both hiring department and origin of the candidate's doctorate. I first examined whether there is a correlation between the mean PGR scores of the hiring and PhD granting department. This correlation is statistically significant, $r(1258)=$ $0.383, \mathrm{p}<.001$, but only has a medium effect size, probably owing to the fact

11. The rankings I used were retrieved from http://www.philosophicalgourmet.com/overall.

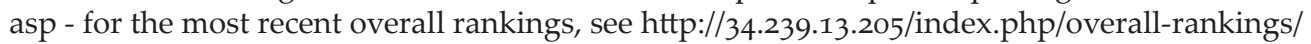

12. The most recent hiring data, for 2012-2017, are available upon request through the e-mail address provided on the website http://placementdata.com/about/ or can be consulted online.

13. At the time the list was provided to me, June 2017. The total number of tenure track/permanent lectureship hires for 2017 was not known then. 
that highly-ranked candidates get hired at departments of different ranks, including unranked departments, as we will see shortly. ${ }^{14}$

I then categorized both the placement and doctoral departments in the following three types: (1) not PGR-ranked, (2) ranked by the PGR, outside the top 20, and (3) PGR-ranked in the top 20. As can be seen in Table 1, most hires reported in the Academic Placement Data and Analysis project are in unranked schools: 976 hires out of a total of 1254 , i.e., $77.8 \%$. This is unsurprising, given that most schools are unranked. In this time period, top-20 programs made a total of 97 tenure track/permanent lecturer hires, $7.7 \%$ of the total number of hires. The data show that people from unranked schools do get hired: 390 candidates (31.1\% of all hires) were people without PGR pedigree. However, candidates from the top-20 schools supplied a large number of all hires, $36.8 \%$. Among the 97 tenure track/permanent lecturer hires in the top-20 schools, there was only one candidate from an unranked school: this candidate had a degree from the Catholic University of America (not PGR ranked), and was hired at the University of Notre Dame (PGR rank 17). The overwhelming majority of hired candidates $(90.7 \%, \mathrm{~N}=88)$ at the PGR top 20 had their PhD degree from another PGR top-20 school. Figure 1 visualizes this dynamic: job seekers who have their degrees from top-PGR departments get jobs at all ranks, including at unranked departments, but the PGR top-20 institutions mostly hire from similarly ranked departments. This is very much in line with findings from other disciplines: lower-ranked departments hire candidates from higher-ranked institutions, but highly-ranked departments do not regularly recruit among lower-ranked doctoral schools. The situation in philosophy appears to be less elitist than in English, but is still in line with a preference for candidates from prestigious schools (prestige bias).

This lack of social mobility may manifest itself before students enter graduate school. Schwitzgebel (2011) found that philosophy graduate students enrolled at Berkeley and Princeton, two PGR top-20 institutions that published the undergraduate pedigree of their graduate students, mainly hail from other PGRranked universities. Of the 121 graduate student profiles he examined, nearly $30 \%$ came from just eight universities. Only three of the universities from which these graduate students got their undergraduate degree were absent from the top 100 of the US News and World Report rankings, but they were ranked well for philosophy (e.g., Rutgers). I looked at a more recent sample, namely the $42 \mathrm{PhD}$ students listed at the New York University philosophy department who were enrolled in 2017, ${ }^{15}$ which is currently ranked $I$ in the PGR. Of these, 40 had their undergraduate or master's listed on the website or their personal homepage. The majority of current NYU PhD students in philosophy $(75 \%)$ have their earlier de-

14. A linear regression could not be calculated because the residuals did not follow a normal distribution.

15. http://as.nyu.edu/philosophy/directory/students.html 
Table 1. Placement of candidates from doctoral departments outside of the PGR, in the PGR outside the top-20, and in the PGR top-20 as reported in the Academic Placement Data and Analysis project (2012-2017).

\begin{tabular}{lcccc}
\hline & $\begin{array}{c}\text { Placements in } \\
\text { institutions } \\
\text { outside PGR }\end{array}$ & $\begin{array}{c}\text { Placements in } \\
\text { institutions in the } \\
\text { PGR outside top 20 }\end{array}$ & $\begin{array}{c}\text { Placements in } \\
\text { institutions in } \\
\text { the PGR top 20 }\end{array}$ & Totals \\
\hline $\begin{array}{l}\text { Candidates from } \\
\text { unranked schools }\end{array}$ & 375 & 14 & 1 & 390 \\
$\begin{array}{l}\text { Candidates from PGR } \\
\text { ranked schools outside } \\
\text { top 20 }\end{array}$ & 328 & 67 & 8 & 403 \\
$\begin{array}{l}\text { Candidates from PGR } \\
\text { top 20 ranked schools }\end{array}$ & 273 & 100 & 88 & 461 \\
\begin{tabular}{l} 
Totals \\
\hline
\end{tabular} & 976 & 181 & 97 & 1254 \\
\hline
\end{tabular}

Origin of $\mathrm{PhD} \quad$ Placement institution

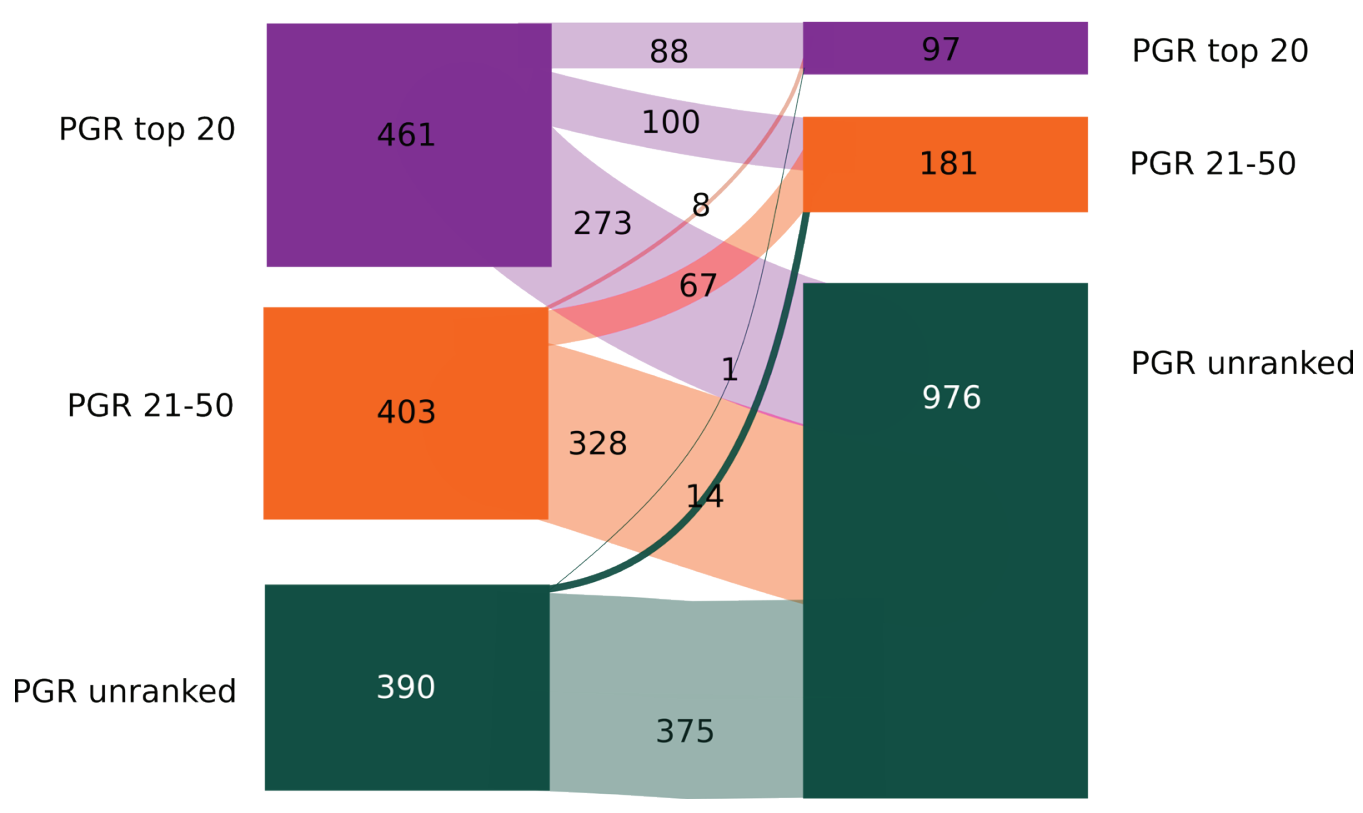

Figure 1. Streams of placements from three different kinds of $\mathrm{PhD}$ granting institutions: PGR top 20 (purple), PGR top 21-50 (orange), and unranked (green) (2012-2017). 
gree from PGR-ranked departments. These schools include Oxford (32.5\%, PGR rank 2), Princeton (7.5\%, PGR rank 3), and Berkeley (7.5\%, PGR rank 11). The unranked departments included foreign schools such as Humboldt University of Berlin, Monash University, and the University of Cape Town. More systematic research would need to be done to confirm the role of undergraduate departmental prestige to graduate admissions, but these findings indicate an influence.

Prestige bias also plays a role in later career development, such as the evaluation of grant applications and REF (Research Excellence Framework) assessments. The REF is intended to measure the quality of research outputs (papers, monographs, etc.) by British faculty members, in order to produce rankings of departments by discipline, and to allocate future funding for research. Publications are awarded between one and four stars, from unclassified to worldleading. There are no hard criteria or metrics for the number of stars to award. Because the researchers whose work is reviewed are not anonymous and evaluations of research are to some extent subjective, evaluations can become biased. Using data that are available in the public domain, Dix (2016) found significant bias in evaluations for the REF: prestigious, research-focused institutions, mostly from the Russell Group (which are regarded as the most prestigious universities), benefit from prestige bias at the expense of more teaching-focused, newer universities (the so-called post-92 universities). As Dix writes,

outputs that would appear equivalent based on external citations are scored far more highly if it comes from a known 'good' institution. In terms of money, it suggests that new universities may be awarded up to two thirds less research funding than might have received under a blind system. (2016)

\section{Prestige as a Measure of Quality}

One reason for the correlational data presented in the previous section might be that prestige tracks quality: candidates who attend prestigious schools could be on average of higher quality, and job hires track this quality, rather than prestige per se. Perhaps because there would be a correlation between prestige and quality, departments could justifiably use the former as an indicator for the latter. In order for prestige to be a useful indicator of quality, two conditions need to be met: first, it needs to be the case that prestige is a reliable indicator of philosophical talent, and second, everyone of equal merit should have equal access to prestige (otherwise we might be overlooking meritorious candidates who might not have had access to prestigious schools). In this section, I argue that the first condition is not met, by showing that it is sometimes the case that there are 
equally good candidates (on measures other than quality), where the prestigious candidate is more likely to be preferred. In Section 5, I will argue against the second condition: prestige bias disadvantages some groups of philosophers more than others.

To examine how, if at all, prestige might measure quality, it is useful to clarify what quality might mean. At least at the stage of hiring junior candidates, quality is not expertise or a proven track record of excellence. If it were, we would expect more seasoned candidates with a larger number of publications to have greater success on the job market. But in philosophy departments in the US, like in other disciplines, there is a preference for hiring relatively inexperienced candidates who have just received their PhD or are still in the All But Dissertation (ABD) stage. Among philosophers who obtained their PhDs between 2012 and 2014 and who managed to obtain tenure-track positions, $42 \%$ received their offer in the year they graduated (Jennings et al. 2015). More recent placement data (Jennings, Cobb, Kallens, \& Kyrilov 2017) reveal that the probability of obtaining a permanent position decreases over time. There is a 1 in 5 chance to be hired while ABD to first year of graduation, 1 in 8 in the second and third year after graduation, dropping steadily to 1 in 23 seven years after graduation. While these figures do not take into account baseline probability rates (people who did not get a job right away might have been weaker candidates), it indicates that measures of established teaching excellence and publication record only play a modest role (at best) in hiring decisions.

Given that students increasingly publish during their graduate studies, one might argue that a successful track record of papers has already been established by the time candidates go on the market. Unfortunately, the most recent placement data (Jennings et al. 2017) do not list the number of publications per candidate. Earlier calculations for hiring in 2012 indicate that candidates hired in tenure track positions have a median of 2 publications: people from unranked departments have more publications than people from ranked departments. ${ }^{16}$ The correlation was negative, but small $(\mathrm{r}=-.17)$ : the lower the rank of the $\mathrm{PhD}$ granting institution, the more papers in peer-reviewed journals a candidate was likely to have (the effect size here is very modest so we cannot draw any firm conclusions at this point).

At the stage of being hired in a tenure track position, quality might reflect promise or potential. A search committee member might reason as follows "a candidate with a $\mathrm{PhD}$ from a prestigious university is more likely to develop a quality track record", that is, is a more promising candidate. This quest for potential and promise might be explained by a widespread belief in innate ability among professional philosophers. Leslie, Cimpian, Meyer, and Freeland (2015)

16. http://philosophysmoker.blogspot.co.uk/2012/o4/to-get-job-in-philosophy.html 
surveyed academics from 30 disciplines in the US to examine whether belief in a field-specific aptitude or talent could explain the underrepresentation of women and African-Americans. Of the examined disciplines in the social sciences and humanities (e.g., sociology, anthropology, and linguistics), philosophy showed the highest belief in field-specific ability, measured by agreement to the following statement: "Being a top scholar in [philosophy] requires a special aptitude that just can't be taught." Participating philosophers also tended to believe that this attitude was prevalent in their discipline. Such beliefs may play a role in hiring decisions, by looking for potential that indicates a special aptitude for philosophy, even if that aptitude is not yet realized in the form of an established publication record.

However, it is hard to measure potential, or to test whether measures for quality in terms of potential are reliable (see also Bright, 2017b). A large body of literature from a variety of job sectors, including academic and non-academic fields (see Kuncel, Klieger, Connelly, \& Ones 2013 for a meta-analysis), suggests that holistically measuring quality from job application materials and interviews (rather than more quantitative measures) tends to produce poor hiring decisions. Once search committees have made a first cut based on minimum requirements (e.g., $\mathrm{PhD}$ in philosophy, right area of specialization), predicting how well someone will fare in their future job based on application materials is notably difficult. For instance, $70-80 \%$ of the variation in job performance of people hired at senior levels in management is unpredictable at the hiring stage (Highhouse 2008).

In retrospect, it is also hard to ascertain whether the hiring decision was correct. For instance, when potential is not realized, we do not know whether it is because a candidate's quality has changed over time, or whether we were mistaken about them (Bright, 2017b). It is also difficult to rely on quality evaluations in terms of potential, because they can become a self-fulfilling prophecy. Several years after hiring, once a candidate has built up a significant publication record and national or even international reputation, it is possible to get some sense of whether the candidate's job performance is good (reflecting some form of quality). But it is unsurprising that job applicants hired at research-intensive universities would do well several years down the line. Take Chris and Daryl, who both apply for a position at a prestigious research-intensive university. Chris is hired; Daryl fails to land a tenure-track position in the same year. Chris obtains a 2-2 position that allows for pre-tenure sabbaticals and research leave. Chris has research support (e.g., funding for conference travel and books). The university regularly hosts major events, including lecture series, colloquia, and conferences, featuring renowned and up-and-coming visiting speakers. This helps Chris get a good sense of the latest topics of interest in their discipline, and helps them to build out an international network. Daryl obtains a one-year Visiting Assistant 
Professor position at a teaching-intensive school, having to teach eight courses per year, followed by a string of other short-term positions, including adjunctships. Daryl lacks funding for conferences or books, office space, and even reliable library access. Daryl attempts to improve their publication record, but the stresses of successive job applications and relocations eat away at their productivity. Five years further, Chris is on course to achieve tenure with an impressive publication record, while Daryl is struggling, a clear instance of the Matthew effect. The Matthew effect describes any form of cumulative advantage (whether economic or cultural) that accrues over time, whereby those rich in resources tend to accumulate advantages more easily, and those poor in resources face increasing difficulties, thus amplifying disparities between resource-rich and resource-poor individuals. The related concept of Matthew mechanism (Bask \& Bask 2015) describes the processes through which this widening gap occurs. Researchers who obtain a tenure-track position while $\mathrm{ABD}$ or freshly minted $\mathrm{PhD}$ have more resources (e.g., in terms of academic support) and fewer stressors (e.g., low pay, frequent moves), compared to academics who do not land such positions immediately.

Moreover, the few studies that have compared doctoral prestige to other measures (e.g., how well the candidate published during graduate school, how much their work was cited, and how quickly they submitted their PhD dissertation) found that prestige had only a small effect on future productivity, but a large effect on placement (see, for example, Baldi 1995 for a study among sociologists). Given that US academic institutions often have ballpark figures for research productivity that are required for tenure, future productivity is an important consideration for whether or not someone would be a successful hire at a tenure track job. ${ }^{17}$

Taken together, this suggests that it is hard to assess future academic success at the stage of hiring, that it is difficult to check whether assessments on the basis of candidate quality are correct or a self-fulfilling prophecy due to the Matthew effect and mechanism, and that prestige is only a modest predictor of future academic productivity. In the light of this, it would seem prudent not to rely unreflectively on prestige as a measure of quality. Yet, as we have seen, philosophers do rely on prestige in hiring decisions. They do so because it provides an easy way to whittle down a large pile of applications to a more manage-

17. For example, at Florida State University, a philosopher who comes up for tenure and promotion to Associate Professor would need something in the order of five refereed articles plus two further units, or a published book and two articles, all of sufficient quality and beyond the candidate's PhD dissertation. See here: http://philosophy.fsu.edu/sites/g/files/imported/storage/ original/application/75dcocd 3 f63861dco3c87575de5c7945.pdf. Many other institutions have quantitative norms, in addition to qualitative norms (i.e., the papers or books need to be of sufficient quality, and there need to be at least $n$ of them, with $n$ varying per institution). 
able one. Typical job applicant dossiers in the US contain a cover letter, research statement (sometimes also a dissertation abstract), CV, teaching statement, and other evidence of teaching competence (such as evaluations and syllabi), a writing sample, and three letters of reference. In the UK, the file tends to be thinner, consisting of a cover letter, $\mathrm{CV}$, writing sample, and contact details of reference writers (whose letters are typically only solicited at the shortlisting stage). Substantial dossiers made sense when the number of applicants for any tenure track job was modest by today's standards. At present, with hundreds of applications for most openings, it is impossible for search committee members to read all this on top of regular teaching, research, and administrative duties (Herlihy-Mera 2015: 88). Using the prestige of the doctoral granting department has become a practical shortcut. As Marinoff explains the hiring procedure at City College, New York (an unranked department):

How did we prune our field from 637 to 27 ? An important selection criterion was holding a Ph.D. from a good university. Members of our department earned their Ph.D.s at Columbia, Harvard, Oxford, and University of London. Additionally, City College is known as the "Harvard of the Proletariat," with distinguished alumni that include nine Nobel Laureates, more than any other public institution in America. Our faculty members are expected to live up to this legacy. (2009)

Quantitative evidence suggests that the prestige of the $\mathrm{PhD}$ granting department plays a role in hiring decisions independent of other qualities a candidate might have. Bedeian, Cavazos, Hunt, and Jauch (2010) looked at a large sample of graduate placements in management and found that the prestige of the doctoral department interacted with perceived quality of publications. Early career graduates from top departments tended to get more prestigious initial appointments compared to graduates from lower-ranked institutions with equally strong publication records who entered the job market. This does not indicate that there is no correlation between prestige and quality, but it does show that in some cases, equally good candidates were treated unequally due to prestige factors. ${ }^{18}$ Headworth and Freese (2016) looked at candidate placement in sociology, taking into account both the prestige of the journals the job candidates published in, and the awards they won. After controlling for these two factors, Headworth and Freese still found

an enormous association between $\mathrm{PhD}$ institution and placement in the set of jobs we consider. The over $40 \%$ of doctorates who receive their de-

18. Thank you to an anonymous referee for raising this point. 
grees from schools in the lowest-prestige tier are entirely absent from the most prestigious sociology research jobs and virtually absent even from our broader set of all rated jobs. (2016: 1275-1276)

The first claim is in line with what we have seen for philosophy, where candidates from the lowest-prestige universities are absent in the top departments. But the second claim does not hold true for philosophy: people from unranked schools do land tenure-track jobs. Headworth and Freese (2016) think that prestige of the $\mathrm{PhD}$ granting university is used as a proxy for quality, trumping factors such as publications in prestigious journals and winning prestigious awards.

Prestige is an indicator of social and cultural capital, and might be valued for indicating these. By hiring a candidate from a prestigious institution, the hiring committee and faculty might hope to get the prestige to rub off on them. Building upon conceptual analysis by Bourdieu (1986), ${ }^{19}$ Burris (2004) investigated prestige in academia as a form of social capital, focusing on sociology, history, and political science. Bourdieu $(1986 ; 1988)$ drew a distinction between economic, cultural, and social capital. Economic capital represents one's economic resources (such as property rights and money). Cultural capital consists of one's cultural resources, such as dispositions (etiquette, tastes that are deemed appropriate), books and other sources of knowledge, and formal educational qualifications. Social capital represents one's social network and relationships, often in the form of membership of a particular social circle-the more exclusive and desirable the circle, the more valuable one's social capital. The latter form of capital is concretely expressed in the form of interpersonal relationships, such as friendships, marriages, and networks. In the case of academia, this can be a $\mathrm{PhD}$ from a prestigious university, being hired at a prestigious university, or being part of a network of people at prestigious institutions. People may try to convert one form of capital into another. For example, someone can try to put their education (cultural capital) to acquire a well-paying job (resulting in economic capital), or someone with money but no social standing might want to marry into a more established family with high social but little economic capital (e.g., impoverished nobility). In spite of being perhaps the least tangible of these capitals, social capital is the most resistant to change. It is protected by exclusive club memberships. People who try to get into exclusive social groups are derisively referred to as upstarts or social climbers. The fact that social mobility in academia is mainly downward, not upward can be explained in terms of Bourdieu's (1986) distinction between the types of capital. Lesser-ranked departments are "eager to exchange their economic capital (faculty positions and salaries) for

19. See also Bourdieu's Homo Academicus (1988), a study of the forms of social and cultural capital in French academia. 
the increment in prestige they hope to gain by hiring the graduate of a highly ranked department" (Burris 2004: 245). The net result is that prestige hierarchies are maintained, as highly-ranked department graduates quasi-monopolize employment. It can explain why rankings remain remarkably stable even as faculty members move department or retire. If a department were to lose a large number of its prominent faculty members in a short period of time, this might result in a shift in social capital and thus affect the ranking. Since faculty moves are limited, rankings will be maintained because institutional networks (e.g., who hires from whom) tend to transcend individual faculty members. Prestige may also be an indicator of cultural capital, as faculty at top departments tend to have a better feel for the "rules of the game", for instance, by submitting more to top journals and working more on "core topics" (see Section 5.2 for preliminary empirical evidence to support this claim). Such a sensibility for the rules of the game is a direct result of moving in the right social circles, and thus of social capital.

This pattern can also be observed in philosophy, where, as we saw, highprestige departments tend to hire primarily from other departments with similar high PGR rankings (see Figure 1). While these data do not, by themselves, establish causation, it would be very odd that almost no candidates from unranked schools were deemed of good enough quality to be hired by a top-20 department. This is at least suggestive of the fact that search committees use departmental prestige (independent of other qualities, which may also play a role in varying degrees) to guide their hiring decisions. How much it guides hiring decisions depends on the schools and what they look for in candidates. For example, teaching-focused schools will often request more extensive teaching dossiers and letters of recommendation, teaching awards, and other forms of evidence that speak to a candidate's qualities in the classroom, and put less weight on prestige. For researchintensive schools, teaching usually plays a far less prominent role, and prestige becomes more important (see, e.g., Kelsky 2015: Chapters 26 and 27, for comparisons). To sum up, my analysis in this section is not intended to show that there is no correlation whatsoever between prestige and quality - the data do not allow one to draw such a strong conclusion. What they do show is that prestige guides hiring decisions independently of other features a candidate might have, and that the correlation between prestige and quality is unreliable.

\section{Prestige Bias Disproportionately Affects Minorities in Philosophy}

Having shown that prestige is not a reliable measure of quality, I will now examine whether everyone has equal access to it by looking at the effects of prestige bias on minorities in philosophy. Given that rankings of departments (in 
philosophy and other fields) express social capital, one would expect that such departments are populated by people who have the economic, cultural, and social capital to be part of these networks. This leads to an underrepresentation of people who are less well networked in academia.

\subsection{Prestige Bias Leads to an Underrepresentation of Ethnic Minorities and People of Low Socio-Economic Status in Philosophy}

Since the prestige of one's undergraduate school influences one's chances of getting into a prestigious graduate school, it is worthwhile examining why ethnic minorities, including African American and Asian American students, are underrepresented at most American elite institutions. Admission systems tend to privilege wealthy white applicants. For instance, Harvard, Yale, Stanford, Princeton, and Columbia, which are in the PGR top 20, uphold the practice of legacy preferences. Legacy preferences are preferential admissions for the children of alumni. Such practices were originally designed to keep Jewish students out. As Karabel (2005) details, a focus on academic performance led to an increase of admissions of Jewish students of Eastern European descent in the early $20^{\text {th }}$ century. To solve this "Jewish problem," (Karabel 2005: 130) and to prevent a "WASP flight" (2005: 134) that would be prompted by what was perceived as an unacceptable increase of non-Christian immigrants, a number of prestigious universities created a new admission system based on legacy preferences and subjective evaluations of character and personality. "By emphasizing the inherently subjective character of admission decisions, the new system of selection left the elite colleges free to adapt to changing circumstances by admittingand rejecting-pretty much whomever they wished" (Karabel 2005: 135). As a result, the background of freshmen in universities such as Harvard, Yale, and Princeton narrowed quickly to include mostly white, wealthy students of WASP backgrounds.

While this system was originally designed to keep Jewish students out, it now continues to exclude Asian and Asian American students. Since the 1980s, empirical evidence consistently shows that Asian Americans outperform all other ethnicity categories in SAT scores and other relevant measures of academic achievement, a difference which seems due to greater academic effort (see, e.g., Hsin \& Xi 2014; Sue \& Okazaki 1990; Zhou \& Lee 2014). In spite of this, the odds of admission for Asian Americans in prestigious US universities are nearly 30\% lower than those of white students. Legacy students are about twice as likely to be accepted as non-legacy students in prestigious institutions (Espenshade, Chung, \& Walling 2004). Therefore, some authors (e.g., Mandery 2014) have argued that legacy preferences perpetuate injustice and should be discontinued.

Other data demonstrate that admission to undergraduate elite institutions 
(and, by extension, graduate school admission and future professional success) is not purely a matter of merit and talent. In 2007, about $15 \%$ of freshmen enrolled at highly selective US colleges were white teenagers who failed to meet their institutions' minimum admissions standards: some secured a place as athletes; others gained admission due to connections to people important for the institutions, in particular donors, faculty members, administrators, and politicians (Schmidt 2007).

But even if athlete studentships and preferential treatment due to social capital were to end, and admissions were to be purely based on measurable criteria, minorities would still be affected by factors outside of their control. The problem is not so much the cost of a tertiary education, since there are student loans and scholarships. Rather, gaining admission to a prestigious university already requires significant advantages, such as access to good primary and secondary education (which, in turn, is sensitive to house prices, or can be bought in the form of private education if no satisfactory public school is nearby), and access to private tutors and other forms of additional support. As Giubilini and Minerva (in press) observe, physiological factors involved in cognitive development are highly sensitive to socio-economic status, with frequent developmental delays in the frontal and temporal lobes of the most economically disadvantaged children (Hair, Hanson, Wolfe, and Pollak 2015). Even if children of low socio-economic status overcome all these hurdles and do well academically, they are still less likely to end up in elite undergraduate and graduate institutions, because of lack of cultural capital: in their cultural milieus there is less awareness of the importance of prestige. While in a middleclass family, the concern for a child on the cusp of higher education would be to get into a "good" school, concerns in working-class families are different: getting into university at all is already regarded as an accomplishment. As the African American philosopher Tommie Shelby (cited in Phillip 2008) observes, "I went to Florida A\&M by chance... . I'm a first generation college student, so no one in my family had really gone and knew the ropes." The same holds true for graduate school: a student from a working-class background does not have the same awareness of the importance of the prestige of a graduate school as a student from a middle-class background.

Taking together these cultural differences between students from the middle class and those from lower socio-economic background, and the extra hurdles that especially first-generation college students face, it is unsurprising that only $14 \%$ of students in US prestigious schools come from the lowest socio-economic background (Walton Radford 2013). Given the distribution of wealth in the US and the UK, those students are disproportionally likely to be people of color, including African Americans in the US and Blacks/Caribbeans in the UK. The wealth gap between white and African-American and Hispanic people has 
increased after the 2008 recession, with whites having 12.9 times as much as African-Americans in net worth, and 10.3 times as much as Hispanics in 2013 (Kochhar \& Fry 2014). In the UK, a large-scale survey by the Office for National Statistics estimated mean net wealth for white households in 2014 at GBP 228,100, compared to GBP 24,700 for Blacks of Caribbean ancestry and GBP 15,300 for Blacks of African ancestry. ${ }^{20}$

Given that students from high-prestige schools dominate the job market, we are now in a position to explain why, for example, black philosophers, who are more likely to come from low socio-economic backgrounds compared to whites, are underrepresented in academic philosophy. Botts, Bright, Cherry, Mallarangeng, and Spencer (2014) calculated that only about $1.32 \%$ of philosophers at US universities (at all professional ranks, including graduate students) are black. Since about $12.3 \%$ of the US population is black, this is a significant underrepresentation. In the UK there are about $1.5 \%$ students who are of Caribbean heritage, but only $0.5 \%$ attend Russell Group universities. Black Africans (3\% of the UK population) make up $4.4 \%$ of total domestic students, ${ }^{21}$ but comprise just 2.1\% of students attending Russell Group universities (Barn 2014). Barn links this differential access to prestigious graduate degrees to the underrepresentation of Black academics:

In an increasingly competitive academic job market, one's pedigree in the form of university background is highly important, with qualifications from elite universities serving as Pavlovian indicators of academic capability. It seems that young black British people are far less likely to attend the UK's most selective universities, a factor which could be making it harder to get academic jobs. (2014)

Looking at publications in prestigious journals, which are important for hiring, tenure decisions, promotions, and senior offers, we also see how prestige filters out ethnic minorities in philosophy. If African American philosophers published proportional to their numbers in the top general journals, one would expect them to have authored about $1.3 \%$ of the contributions. However, Bright (2016) found that in a list of 15 high-prestige philosophy journals (which included both general and specialist periodicals) black philosophers only authored $0.28 \%$ of articles (including book reviews), and only $0.19 \%$ of research papers (i.e., 15 papers) from 2003 to 2012. The low representation of black philosophers in the

20. https://www.ons.gov.uk/peoplepopulationandcommunity/personalandhouseholdfinances/incomeandwealth/adhocs/005233wealthbyhouseholdcharacteristicsforlondonjuly2012toju ne2014

21. This also includes overseas African students. Statistics do not give a breakdown in terms of domestic versus international black students. 
most prestigious philosophy journals thus also has a negative influence on their further chances for career advancement.

\subsection{Prestige Bias Leads to Testimonial Smothering and Silencing of Philosophical Work outside the Dominant Traditions}

Prestige bias can result in testimonial silencing (terminology from Dotson 2011) for work in philosophical traditions that is considered fringe or optional, such as philosophy of race and non-western philosophy. In testimonial silencing people are silenced and not taken seriously as testifiers as a result of their group membership. There are at least two forms of testimonial silencing: testimonial quieting and testimonial smothering. As speakers, we have a certain vulnerability toward our audience. We cannot force others to listen to what we have to say, so any communicative act requires some cooperation on the part of listeners. They need to be both willing and capable to receive testimony. Testimonial quieting occurs when one fails to recognize the speaker as a knower, which damages a speaker's agency. Search committee members who make a first cut of job applications on the basis of the prestige of the doctoral department are engaged in testimonial quieting. They systematically ignore the testimony of applicants who lack the required social capital. It is an injustice that the potential audience is not even willing to look at the merits of a candidate, in terms of publication record, teaching experience, and other measures merely because she does not come from the right school.

Testimonial smothering occurs when a speaker notices that an audience is unwilling or unable to take up her testimony and so "smothers" her own testimony. She will then try to insure that "the testimony contains only content for which one's audience demonstrates testimonial competence" (Dotson 2011: 244). When graduate students and other jobseekers are unable to secure a place at a prestigious graduate school, they might try to compensate for this by changing their topics of work to fit more prestigious fields, in order to get into journals that are highly prestigious.

The most prestigious journals in philosophy tend to be general journals that in principle accept a wide range of papers from different subdisciplines. For instance, Colyvan's ${ }^{22}$ list of (what he thinks philosophers would consider to be) the best journals are Australasian Journal of Philosophy, Journal of Philosophy, Mind, Nô̂s, Philosophy and Phenomenological Research, Philosophical Review, and Philosophical Studies. This is in line with other lists, such as Leiter's 2015 poll of the top-20 general philosophy journals. The top 5 in this poll consists of Philosophical Review, Noûs, Journal of Philosophy, Mind, and Philosophy and Phe-

22. http://www.colyvan.com/journals.html 
nomenological Research. ${ }^{23}$ Brooks's journal rankings for philosophy has the same five journals, ${ }^{24}$ and adds Ethics and Philosophical Quarterly as top-rated journals. While these journals are not necessarily the highest in quality, they are regarded as the most prestigious. The journals avow themselves generalist, but in practice they tend to publish a narrow range of specializations, with a heavy focus on analytic philosophy of language, epistemology, metaphysics, and philosophy of mind, the so-called "Lemming" subdisciplines. This leaves many areas of philosophy underrepresented in these journals.

Consider Asian philosophy, which offers a large and diverse number of traditions, including Chinese and Indian philosophies. Olberding (2016) looked at abstracts in general philosophy journals, many of which were high-prestige, for keywords that one can expect to frequently occur in papers in Asian philosophy: "Confucian", "Buddhist", "Daoist", and "Indian." For each of these journals, articles in Asian philosophy were vanishingly rare. Philosophy and Phenomenological Research was the most fruitful venue, with 19 papers in Asian philosophy appearing in the total time period studied (1940-2014). However, the interest in Asian philosophy had tapered off in this journal as the last article appeared in 1993. Noûs does not have a single article in Asian philosophy in the entire period that was under study (1967-2013). On the whole, the representation of Asian philosophy in general journals has flatlined over the years. Although there is an increasing body of work in Asian philosophy available to English-speaking scholars, with journals such as Journal of Chinese Philosophy, Journal of Indian Philosophy, and Dao: A Journal of Comparative Philosophy, this research does not seem to find its way into the most prestigious venues.

To examine whether area of specialization might discourage submissions to the most prestigious journals, I conducted a survey among academic philosophers $(\mathrm{N}=251,76.9 \%$ men, see appendix for the questions and more details on the survey). I asked respondents if they had submitted to one of the top- 5 general journals in philosophy over the past 12 months. ${ }^{25}$

The majority of respondents (68\%) said they did not submit anything to these journals during this period.

Philosophers who worked in Lemming subdisciplines $(\mathrm{N}=109)$ submitted about twice as much to the top- 5 journals (Mean=.81, $\mathrm{SD}=1.350$ ), compared to scholars who worked outside of these fields $(\mathrm{N}=141)(\mathrm{Mean}=.45, \mathrm{SD}=.906)$. This was a statistically significant difference, following an independent-samples ttest, $t(179.5)=2.35, p=.02$ (two-tailed), albeit with a small effect size, Cohen's $d$

23. http://leiterreports.typepad.com/blog/2015/og/the-top-20-general-philosophy-journals-2015.html

24. http://the-brooks-blog.blogspot.co.uk/2011/og/journal-rankings-for-philosophy_29.html

25. Based on the aforementioned lists, I included the following five journals: Philosophical Review, Mind, Journal of Philosophy, Nô̂s, Philosophy and Phenomenological Research. 
$=0.31$. There was no statistically significant difference in how much Lemmings submitted to any refereed journal compared to non-Lemmings, $t(249)=1.16$, $\mathrm{p}=.248$ (NS). Moreover, non-Lemmings submitted more papers to specialist journals $($ Mean $=1.86, \mathrm{SD}=1.56)$ than Lemmings $($ Mean $=1.07, \mathrm{SD}=1.39), \mathrm{t}(247)=4.1, \mathrm{p}$ $<.01$, Cohen's $d=0.53$, a medium effect size. These data suggest that Lemmings submit more of their work to the top-5 generalist journals, and people outside of Lemming subdisciplines submit more of their work to specialist journals. A possible reason, suggested by the open responses to the question of why participants do not submit to the top prestige journals, is that they are perceived as not welcoming to work outside of the Lemming subdisciplines. A number of respondents gave as reason that their work would not fit in these journals, for example:

"My perception is that the areas in which I work (Continental Philosophy, Philosophy of Race, Aesthetics) would not be taken seriously by these venues. Why waste time?"

"Many people I'd like to read my papers do not typically read those journals."

"I do interdisciplinary work that is more likely to be read by the audience I'm most interested in in specialty journals."

In this way, the prestige of journals leads to testimonial smothering.

\subsection{Prestige Bias Leads to an Underrepresentation of Women in Prestigious Journals}

Does prestige bias play a role in the underrepresentation of women in philosophy? The picture here is less clear-cut than for low socio-economic status philosophers, philosophers from ethnic minorities, and philosophers working in non-dominant subdisciplines. Schwitzgebel and Jennings (2017) note that gender disparity in philosophy is still stark, and that the proportion of women in philosophy is only slowly rising, but they find mixed evidence for their specific hypothesis that gender disparity would be largest for the most prestigious journals, conferences, and schools. Contrary to their hypothesis, they found that the percentage of women faculty members at PGR-ranked departments was similar to the percentage of women in the discipline as a whole, and that on average women did not receive their PhDs from lower-ranked institutions.

By law, departments in the US can use affirmative action policies in hiring and graduate school admission to mitigate the effect of gender bias. This option is not available in many other countries. For example, throughout Europe, af- 
firmative action in hiring is illegal. In the UK (following the Equality Act 2010), the only thing an employer can do to have a staff that reflects the wider society's diversity is to encourage minorities to apply to job advertisements, and host special events for them (e.g., job fairs). An employer can also choose the minority candidate if two candidates are equally well qualified. Women are underrepresented in the most prestigious UK departments. Research-intensive universities, such as those of the Russell Group, have fewer women among their full professors compared to less prestigious institutions. Only 6 of the 24 Russell Group universities have higher than average female representation among the professoriate. The BPA/Good Practice Scheme recognizes this, and prompts organizers of conferences to cast a wider net in order to have a good representation of women: "Women may well be at lower-prestige institutions and/or in lowerranked jobs .... They may therefore have less access to institutional funding." 26

Given the importance of publications in top journals for promotion, senior offers, and increasingly also for junior employment, I will also briefly consider how prestige and gender interact in journal publications. Schwitzgebel and Jennings (2017) found that women were less likely to publish in the top-3 general philosophy journals (Philosophical Review, Journal of Philosophy, Mind), and in the top specialist journals for ethics (Ethics, Philosophy and Public Affairs). Only $12 \%$ of authors in these journals in the period 2013-2015 were women, which is substantially below the percentage of women in the profession (around 21-26\%). A recent study (Wilhelm, Conklin, and Hassoun in press) widened the sample to 25 prestigious journals as ranked by the PGR (2015) for 2004 and 2014-2015. Again, the percentage of women in these journals was very low, 14-16\%, substantially below the percentage of women at US philosophy faculties. It is currently not known whether this underrepresentation of women in the most prestigious journals is due to lower acceptance rates or lower submission rates, due to a lack of information about submission rates. Perhaps the underrepresentation of women in prestigious journals can be explained by lower submission rates. This is not unproblematic, as it would suggest that prestige acts as a barrier for women to submit work to the most prestigious journals. ${ }^{27}$ Journal prestige plays an important role in evaluations of CVs, especially for tenure and promotion decisions, and for grant applications, where $\mathrm{CV}$ and prior experience play an important role in the decision process.

26. Guidelines can be found, for instance, at the British Society of Aesthetics, which provides grants for conferences. One condition of the grants is that organizers of conferences abide by the BPA/SWIP good practice scheme: http://british-aesthetics.org/?portfolio=small-grants.

27. Indeed, several studies (reviewed in Bright 2017a: Section 2) suggest that women in the sciences believe that their work will be held to a greater standard and face more negative scrutiny compared to that of male authors. If this is also true for philosophy, it could explain why women submit fewer papers to high-prestige journals. 
Healy (2013) found that women were not only underrepresented in the most prestigious philosophy journals, but also undercited. He looked at the most cited authors in the top-4 general philosophy journals, Philosophical Review, Journal of Philosophy, Mind, and Noûs. He examined 2200 articles over the past two decades, having a total of 34,000 citations, and focused on papers that have at least 10 citations. This brought to light intricate citation networks, from which women were systematically excluded. Of the most highly-cited papers $(\mathrm{N}=520)$, only $3.6 \%$ were by women. Healy (2015) further found that this disparity was due to a large difference in citation rates of the most highly-cited papers, with highlycited male authors being more cited than highly-cited female authors. While having highly-cited papers in top journals is surely a mark of prestige, one may wonder whether being part of these citation networks matters given how few philosophers publish in these highly-ranked journals, and how few of them are cited at all (most philosophy papers are never cited). However, as Healy (2015) points out, the most highly-cited papers at top journals (i.e., the most prestigious papers) tend to shape the field by being studied by graduate students and ending up in philosophy syllabi. Thus, at a very visible level of prestige, women are suffering from prestige bias. This has downstream effects on syllabi and on the further engagement with women authors in the field.

\section{How to Mitigate Prestige Bias}

Having made the case that prestige bias is an obstacle to a more inclusive and diverse philosophy, I will now look at concrete ways to mitigate its effects. As we have seen, prestige bias already has an adverse effect on diversity at the undergraduate level. In order to counter prestige bias, a wide range of measures would need to be introduced, including improving primary and secondary schools, extra-curricular support for children from lower economic status households, and axing legacy preferences and other college admissions systems that unfairly privilege white, wealthy students. Such extensive policy changes are not easy to implement by individual academics. Nevertheless, there are concrete steps we can take to mitigate prestige bias. I will propose the following three: correct for prestige bias in one's citation practices and syllabi, diminish prestige bias in graduate school admissions, and counter prestige bias in hiring decisions.

Compared to many other disciplines, including other humanities, philosophers tend to cite fewer authors. In such a climate, citations are in danger of becoming a commodity, a favor to be bestowed, presumably in exchange for other goods. ${ }^{28}$ Citing sparingly also makes it more difficult for newcomers in the field

28. The earlier-mentioned citation networks (Healy 2013) are a clear illustration of this. 
to get a grasp of the literature (Schliesser 2015). Citing more generously may be a way to counter this: more citations make citations less of an exchange commodity and mean that papers become more accessible to newcomers. Individual philosophers could also cite more mindfully, taking care to cite minority authors who have substantially contributed to a debate, even if this means citing papers published in less prestigious venues. Something analogous to the Bechdel test could work (De Cruz 2014). If one is worried about underrepresenting women, one could use the simple rule of thumb that one's paper cites at least two women authors, actively engages with at least one woman author (i.e., not just citing but engaging with her work), and does not solely mention women because they write about a male philosopher. ${ }^{29}$ One could use analogous rules for other minorities.

Next to citation practices, philosophers can take an active role in reducing prestige bias when vetting graduate school applications. For instance, in 2015 Pennsylvania State University awarded PhDs to five black, female philosophers, which is an unusually high number given the low representation of African Americans in philosophy, especially women. Robert Bernasconi, who was involved in the admission process, argues that his attempts to diversify were successful in part because they actively tried to counteract prestige bias:

Philosophy doctoral programs, and doctoral programs in general, pay too much attention to a student's résumé and academic pedigree, an attitude that perpetuates privilege. The question he [Bernasconi] asks himself while reviewing applications is: With five years of intensive preparation, will the student be as good as any other new Ph.D.? "I read the writing samples very carefully," he says, "I'm looking for a spark, something that suggests insight." (Patel 2016)

Philosophers can also choose to decrease prestige bias in their hiring decisions. Recently, two philosophy faculties (Sheffield, UK and Miami, US) aimed to reduce bias in their hiring by anonymizing applicants in the early stages of the search and by changing the weight placed on different parts of the application. Both departments used anonymous CVs. Note that markers of prestige were not omitted from the applications: the anonymized CVs still contained the doctoral

29. The original Bechdel test is about works of fiction and a work passes the test if it (1) features at least two women, (2) who talk to each other, (3) about something other than a man. I am grateful to David Chalmers for proposing the third element of the philosophy paper Bechdel test; I think the third element is defeasible in areas such as history of philosophy, where the baseline rate of philosophers discussing male authors is very high. However, even there, a philosopher could take care to cite women in the secondary literature, e.g., for Kant scholars, Onora O'Neill, Jill Buroker, or Lisa Shabel. 
school where the candidate graduated, and the names of journals in which the candidate published. The aim of these searches was not specifically to reduce prestige bias, but rather to reduce bias overall. Jennifer Saul (Sheffield, personal communication) explained how her department cut down a list of about 150 applications. Instead of making a ranking of candidates, search committee members looked at anonymized CVs and asked if they met two criteria: whether the applicant could teach in the relevant areas and whether they had a publication record that made them look suitable for the next REF. On the basis of these criteria, they retained 20 candidates. This procedure is less holistic than the typical search, and thus reduces bias overall. Members of the search committee subsequently read writing samples and created a shortlist. Letters of reference hardly played a role, which may have mitigated the bias in favor of famous letter writers.

Miami had 600 anonymous applications; the department distributed anonymized writing samples of all applicants to external referees. On the basis of these referee reports, they created a long list of 20 candidates. They held Skype interviews and looked at letters of reference (mainly to spot potential problems with candidates). After these interviews, they invited a few interviewees to campus. While this process did not eradicate prestige bias, it did decrease it (particularly in the early stages as the writing samples were anonymized). As Berit Brogaard (Miami, personal communication) writes, "We did end up hiring someone with a $\mathrm{PhD}$ from a German university, which may not have happened if we had not gone anonymous." In both searches, prestige bias was not completely eliminated, but it was made less salient than it would otherwise be, given the reduced importance of letter writers and the use of non-prestige criteria (writing samples, publication record, and teaching competence) as deciding factors. Citation practices, graduate school admissions and hiring practices indicate that individual philosophers can go some way to mitigate prestige bias, and hence create a fairer playing field for the discipline.

\section{Concluding Remarks}

Not many philosophers object to the role of prestige in their discipline in making hiring and promotion decisions, and in deciding who and what to cite. As I have shown, prestige bias generates and exacerbates different forms of inequality in philosophy and facilitates exclusion of minorities, including ethnic minorities, women, and philosophers who work outside of dominant traditions. I have argued that prestige bias is harmful, in part, because it disproportionately affects minorities. Assuming that checks and balances were somehow in place to guard against this, would this make prestige bias acceptable? Presumably not, because of prestige bias' inability to track what it allegedly tracks 
(quality, philosophical talent), and its arbitrary preference for some philosophers over others. I have centered my argument on the exclusion of minorities, because it is something philosophers seem to be nearly unanimous in seeing as a bad feature of the profession.

Prestige bias is both the first and the final hurdle to make academic philosophy more inclusive. It is the first hurdle because countering it provides a wide-reaching way to make philosophy more diverse even if we did not make any other efforts to increase diversity. By actively countering prestige bias in our assessment of doctorate-granting institutions, journals, topics to work on, and authors to cite, we can get diversity on the cheap. We can cast a wider net in recruiting and retaining young philosophers, and many philosophical ideas can flourish. Prestige bias is also the final hurdle, because it has been relatively unchallenged compared to other biases. I have shown that individual philosophers can mitigate prestige bias through relatively simple adjustments in their citation practices, graduate school admissions, and hiring processes.

\section{Acknowledgments}

I wish to thank Ian James Kidd, Liam Kofi Bright, Richard Pettigrew, Johan De Smedt, Tim Kenyon, Eric Schwitzgebel, Olivier Morin, two anonymous referees, an anonymous area editor, and audiences at Bristol and Nottingham for comments to earlier versions of this paper. I also wish to thank Carolyn Dicey Jennings for providing me with the raw hiring data, and Jennifer Saul and Berit Brogaard for discussions on anonymized hiring practices.

\section{Appendix: Questionnaire and Methodology Used for Survey on Who Submits to Top 5 Journals}

Survey conducted September 2014, spread via philosophy blogs and mailing lists.

1. In your estimation, since September 2013, how many papers in total did you submit to any of the following: Philosophical Review, Journal of Philosophy, Nô̂s, Philosophy and Phenomenological Research, Mind? Do not include resubmissions, only original submissions in your count.

2. (If answer is o) Why did you not submit to any of these journals? (select all that apply) The review time is too long/The probability of acceptance is too low/The journal I wanted to submit to didn't accept new submissions/ The papers I wrote during that period do not fit in these journals/ Other reasons (please explain briefly) 
3. In your estimation, since September 2013 , how many papers did you submit to any refereed journal (philosophical or otherwise)? This does not include resubmissions, but only original papers.

4. In your estimation, since September 2013, how many papers did you submit to specialist journals? This does not include resubmissions, but only original papers.

5. What is your gender? (Male/female/other)

6. How would you describe your institution? (please select all that apply) (public/ private/small liberal arts college/R-1 (research oriented)/ranked in the PGR top 15/ Ivy League (in US) or similar status outside of US/ Teaching-oriented/focused/I do not have an institutional affiliation)

7. What is your academic position? (Graduate student, tenure-track faculty, tenured faculty, non-TT faculty, adjunct or other part-time teaching position, non-academic, unemployed)

8. What is your ethnic identity? (White, African-American or Black, Asian, Hispanic, Mixed, Other)

9. What are your areas of specialization (select all that apply)? (list of academic specializations, e.g., epistemology, philosophy of language, philosophy of race, other)

\section{References}

Ayala, Saray (2015). Philosophy and the Non-Native Speaker Condition. APA Newsletter: Feminism and Philosophy, 14(2), 2-9.

Baldi, Stéphane (1995). Prestige Determinants of First Academic Job for New Sociology Ph.D.s 1985-1992. The Sociological Quarterly, 36(4), 777-789. https://doi. org/10.1111/j.1533-8525.1995.tb00464.x

Barn, Gulzaar (2014). Academic Racism, and the Problems with 'Race' as a Scientific Category. The Oxford Left Review. Retrieved from https://oxfordleftreview.com/academic-racism/

Baron, Sam, Tom Dougherty, and Kristie Miller (2015). Why is there Female UnderRepresentation among Philosophy Majors? Evidence of a Pre-University Effect. Ergo, 2(14), 329-365.

Bask, Mila and Michael Bask (2015). Cumulative (Dis)advantage and the Matthew Effect in Life-Course Analysis. PloS ONE, 1O(11), eo142447. https://doi.org/10.1371/journal. pone.0142447

Bedeian, Arthur G., David E. Cavazos, James G. Hunt, and Lawrence R. Jauch (2010). Doctoral Degree Prestige and the Academic Marketplace: A Study of Career Mobility within the Management Discipline. Academy of Management Learning \& Education, 9(1), 11-25. https://doi.org/10.5465/AMLE.2010.48661188

Botts, Tina F., Liam K. Bright, Myisha Cherry, Guntur Mallarangeng, and Quayshawn Spencer (2014). What is the State of Blacks in Philosophy? Critical Philosophy of Race, 2(2), 224-242. https://doi.org/10.5325/critphilrace.2.2.0224 
Bourdieu, Pierre (1986). The Forms of Capital. In John G. Richardson (Ed.), Handbook of Theory and Research for the Sociology of Education (241-258). Greenwood.

Bourdieu, Pierre (1988). Homo Academicus. Stanford University Press.

Bright, Liam K. (2016, January 18). Publications by Black Authors in Leiter Top 15 Journals 2003-2012 [Web log post]. Retrieved from http://schwitzsplinters.blogspot. co.uk/2016/01/publications-by-black-authors-in-leiter.html

Bright, Liam K. (2017a). Decision Theoretic Model of the Productivity Gap. Erkenntnis, 82(2), 421-442. https://doi.org/10.1007/s10670-016-9826-6

Bright, Liam K. (2017b). Against Candidate Quality. Manuscript in preparation.

Brownstein, Michael and Jennifer Saul (2016). Implicit Bias and Philosophy: Metaphysics and Epistemology (Vol. 1). Oxford University Press. https://doi.org/10.1093/acprof:o so/9780198713241.001.0001

Bruya, Brian (2015). Appearance and Reality in the Philosophical Gourmet Report: Why the Discrepancy Matters to the Profession of Philosophy. Metaphilosophy, 46(4-5), 657-69o. https://doi.org/10.1111/meta.12161

Burris, Val (2004). The Academic Caste System: Prestige Hierarchies in PhD Exchange Networks. American Sociological Review, 69(2), 239-264. https://doi. org $/ 10.1177 / 000312240406900205$

Clauset, Aaron, Samuel Arbesman, and Daniel B. Larremore (2015). Systematic Inequality and Hierarchy in Faculty Hiring Networks. Science Advances, 1(1), e1400005. https://doi.org/10.1126/sciadv.1400005

De Cruz, Helen (2014, April 3). A Bechdel Test for Philosophy Papers [Web log post]. Retrieved from http://www.newappsblog.com/2014/04/a-bechdel-test-for-philosophypapers.html

Dix, Alan (2016, March 22). Evaluating Research Assessment: Metrics-Based Analysis Exposes Implicit Bias in REF2014 Results. Retrieved from http://blogs.lse.ac.uk/ impactofsocialsciences/2016/03/22/ref2014-and-computer-science-and-informaticssubpanel/

Dotson, Kristie (2011). Tracking Epistemic Violence, Tracking Practices of Silencing. Hypatia, 26(2), 236-257. https://doi.org/10.1111/j.1527-2001.2011.01177.x

Espenshade, Thomas J., Chang Y. Chung, and Joan L. Walling (2004). Admission Preferences for Minority Students, Athletes, and Legacies at Elite Universities. Social Science Quarterly, 85(5), 1422-1446. https://doi.org/10.1111/j.0038-4941.2004.00284.x

Giubilini, Alberto and Francesca Minerva (in press). Enhancing Equality. Journal of Medicine and Philosophy.

Gross, Neil and Solon Simmons (2014). The Social and Political Views of American College and University Professors. In Neil Gross and Solon Simmons (Eds.), Professors and their Politics (19-52). Johns Hopkins University Press.

Hair, Nicole L., Jamie L. Hanson, Barbara L. Wolfe, and Seth D. Pollak (2015). Association of Child Poverty, Brain Development, and Academic Achievement. JAMA Pediatrics, 169(9), 822-829. https://doi.org/10.1001/jamapediatrics.2015.1475

Headworth, Spencer and Jeremy Freese (2016). Credential Privilege or Cumulative Advantage? Prestige, Productivity, and Placement in the Academic Sociology Job Market. Social Forces, 94(3), 1257-1282. https://doi.org/10.1093/sf/sov102

Healy, Kieran (2013, June 19). Lewis and the Women [Web log post]. Retrieved from https://kieranhealy.org/blog/archives/2013/06/19/lewis-and-the-women/

Healy, Kieran (2015, February 25). Gender and Citation in Four General-Interest Phi- 
losophy Journals, 1993-2013 [Web log post]. Retrieved from https://kieranhealy.org/ blog/archives/2015/02/25/gender-and-citation-in-four-general-interest-philosophyjournals-1993-2013/

Herlihy-Mera, Jeffrey (2015). Academic Imperialism; Or, Replacing Nonrepresentative Elites. Democratizing English Departments at Top-ranked US Institutions. Minnesota Review, 2015(85), 80-106.

Highhouse, Scott (2008). Stubborn Reliance on Intuition and Subjectivity in Employee Selection. Industrial and Organizational Psychology, 1(3), 333-342. https://doi. org/10.1111/j.1754-9434.2008.00058.x

Hsin, Amy and Yu Xie (2014). Explaining Asian Americans' Academic Advantage over Whites. Proceedings of the National Academy of Sciences USA, 111(23), 8416-8421. https://doi.org/10.1073/pnas.1406402111

Jennings, Carolyn D., Angelo Kyrilov, Patrice Cobb, Justin Vlasits, David W. Vinson, Evette Montes, and Franco Cruz (2015). Academic Placement Data and Analysis: 2015 Final Report. Retrieved from

http://c.ymcdn.com/sites/www.apaonline.org/resource/resmgr/ grantreports/2015apdareport.pdf

Jennings, Carolyn D., Patrice Cobb, Pablo C. Kallens, and Angelo Kyrilov (2017). Academic Placement Data and Analysis: 2017 Final Report. Retrieved from http://dailynous.com/2017/10/02/philosophy-phd-program-rankings-apdas-2017-final-report/

Karabel, Jerome (2005). The Chosen: The Hidden History of Admission and Exclusion at Harvard, Yale, and Princeton. Houghton Mifflin.

Kelsky, Karen (2015). The Professor is In. The Essential Guide to Turning Your PhD into a Job. Three Rivers Press.

Kidd, Ian James (2017). Resisters, Diversity in Philosophy, and the Demographic Problem. Rivista di Estetica, 64, 118-134. https://doi.org/10.4000/estetica.2071

Kocchar, Rakesh and Richard Fry (2014, December 12). Wealth Inequality Has Widened along Racial, Ethnic Lines Since End of Great Recession. Retrieved from http://www. pewresearch.org/fact-tank/2014/12/12/racial-wealth-gaps-great-recession/

Kuncel, Nathan R., David M. Klieger, Brian S. Connelly, and Deniz S. Ones (2013). Mechanical versus Clinical Data Combination in Selection and Admissions Decisions: A Meta-Analysis. Journal of Applied Psychology, 98(6), 1060-1072. https://doi. org/10.1037/a0034156

Leslie, Sarah-Jane, Andrei Cimpian, Meredith Meyer, and Edward Freeland (2015). Expectations of Brilliance Underlie Gender Distributions across Academic Disciplines. Science, 347(6219), 262-265. https://doi.org/10.1126/science.1261375

Mandery, Evan J. (2014, April 24). End College Legacy Preferences. New York Times. Retrieved from http://www.nytimes.com/2014/04/25/opinion/end-college-legacy-preferences.html

Marinoff, Lou (2009, August 31). Inside a Search. Inside Higher Education. Retrieved from https://www.insidehighered.com/advice/2009/08/31/inside-search

Olberding, Amy (2016). Chinese Philosophy and Wider Philosophical Discourses: Including Chinese Philosophy in General Audience Philosophy Journals. APA Newsletter: Asian and Asian-American Philosophers and Philosophies, 15(2), 2-9.

Patel, Vimal (2016, March 26). Diversifying a Discipline. Chronicle of Higher Education. Retrieved from http://www.chronicle.com/article/Diversifying-a-Discipline/235851

Phillip, Abby. (2008, November 19) Living to Learn. The Harvard Crimson. Retrieved from 
http://www.thecrimson.com/article/2008/11/19/living-to-learn-harvards-africanand/

Schliesser, Eric (2015, April 20). Citation as Status Signaling [Web log post]. Retrieved from http://digressionsnimpressions.typepad.com/digressionsimpressions/2015/04/ citationstatussignals.html

Schmidt, Peter (2007, September 28). At Elite Colleges, Dim White Kids. The Boston Globe. Retrieved from http://archive.boston.com/news/globe/editorial_opinion/oped/articles/2007/09/28/at_the_elite_colleges__dim_white_kids/

Schwitzgebel, Eric (2011, October 27). Sorry, Cal State Students, No Princeton Grad School for You! [Web log post]. Retrieved from http://schwitzsplinters.blogspot. co.uk/2011/10/sorry-cal-state-students-no-princeton.html

Schwitzgebel, Eric and Carolyn D. Jennings (2017). Women in Philosophy: Quantitative Analyses of Specialization, Prevalence, Visibility, and Generational Change. Public Affairs Quarterly, 31(2), 83-106.

Sue, Stanley and Sumie Okazaki (1990). Asian-American Educational Achievements: A Phenomenon in Search of an Explanation. American Psychologist, 45(1), 913-920. https://doi.org/10.1037/0003-066X.45.8.913

Thompson, Morgan, Toni Adleberg, Sam Sims, and Eddy Nahmias (2016). Why Do Women Leave Philosophy? Surveying Students at the Introductory Level. Philosopher's Imprint, 16(6), 1-36.

Walton Radford, Alexandria (2013). Top Students, Top Schools? How Social Class Shapes where Valedictorians Go to College. University of Chicago Press. https://doi.org/10.7208/ chicago/9780226041148.001.0001

Wilhelm, Isaac, Sherri Lynn Conklin, and Nicole Hassoun (in press). New Data on the Representation of Women in Philosophy Journals: 2004-2015. Philosophical Studies.

Zhou, Min and Jennifer Lee (2014). Assessing what is Cultural about Asian Americans' Academic Advantage. Proceedings of the National Academy of Sciences USA, $111(23)$, 8321-8322. https://doi.org/10.1073/pnas.1407309111 
